\title{
TO SUFFER IN PARADISE: COMPARISONS BETWEEN PATIENTS DIAGNOSED WITH SCHIZOPHRENIA LIVING IN THE PORTUGUESE ISLANDS AND MAINLAND
}

\author{
Carolina da Mottaa), Paula Castilhoa), Célia Barreto Carvalhoa), b), Michele T. Patoc),d) \\ a) Center for Research in Neuropsychology and Cognitive and Behavioral Intervention (CINEICC), College of Psychology and Education \\ Sciences, University of Coimbra, Portugal \\ b) Department of Psychology, Faculty of Human and Social Sciences, University of Azores, Azores, Portugal \\ c) Institute for Genomic Health, SUNY Downstate Medical Center, Brooklyn, NY \\ d) Keck School of Medicine, Department of Psychiatry and Behavioral Sciences, University of Southern California.
}

Schizophrenia is a burdensome psychiatric illness that entails significant costs to healthcare, social burden (e.g. caretakers) and psychological consequences, thus requiring a dependable and well-designed multidisciplinary intervention. The current work sought to characterize patients residing in rural areas from the Portuguese islands and mainland territories, exploring the characteristics and functional impairments in patients diagnosed with schizophrenia in Portugal.

\section{METHOD}

Sample: 37 participants, 31 males (83.8\%) and 6 (16.2\%) females diagnosed with schizophrenia were recruited through mental health services and institutions the Portuguese mainland and island territories (São Miguel Island, Azores, and in the central region).

Measures: Community Integration Scale for Adults with Psychiatric Problems - Brief Version (CIS-APP; Cabral, Barreto Carvalho, da Motta \& Sousa, 2018). The CIS-APP is a 12-item self-report measure devised for adults with psychiatric problems, but also applicable for people without mental illnesses. Scores can range from 0 to 60.

USCD Performance-based Skills Assessment 2 (UPSA-2-PT; Patterson et al., 2001, da Motta, Barreto Carvalho, Castilho \& Pato, 2019) evaluates performance in 5 domains in everyday functioning and community living (household chores, comprehension/planning a recreational activity, communication, finance, transportation) through a series of standardized skills performance situations. Scores can range from 0 to 100 .

\section{RESULTS}

Participants from the rural areas from the mainland $(n=23)$ and island $(n=$ 14) territories did not differ regarding sociodemographic characteristics (except for age), occupational status, community integration and access to mental health services.

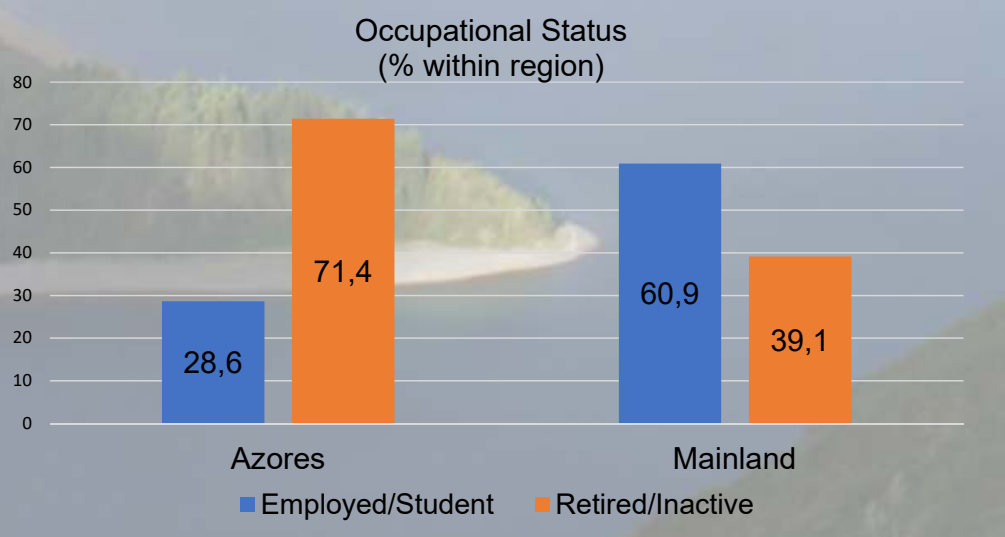

Fig 1. Patient's occupational status $(N=37)$
Participants from the mainland had more positive functional outcomes and occupational status (figs 1 and 2). Statistically significant differences were found regarding functional capacity, age and duration of illness (table 1).

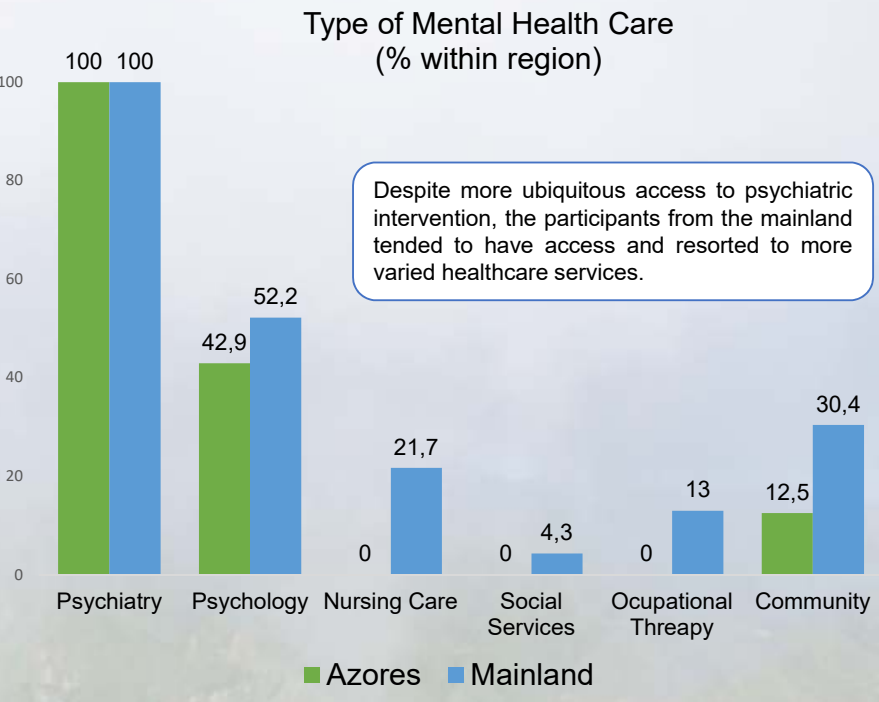

Fig 2. Types of mental health resources used by patients $(N=37)$

Table 2. Group comparison of age, duration of illness, hospitalizations, community integration and funcional outcomes

\begin{tabular}{|c|c|c|c|c|}
\hline & \multicolumn{2}{|c|}{ Mean Rank } & $\begin{array}{c}\text { Mann- } \\
\text { Whitney U }\end{array}$ & p \\
\hline & $\begin{array}{l}\text { Azores } \\
(n=14)\end{array}$ & $\begin{array}{l}\text { Mainland } \\
(n=23)\end{array}$ & & \\
\hline Age & 27.07 & 14.09 & 48.000 & $.000 * *$ \\
\hline $\begin{array}{l}\text { Duration of } \\
\text { illness (years) }\end{array}$ & 27.86 & 13.61 & 37.000 & $.000 * *$ \\
\hline $\begin{array}{l}\text { \# of } \\
\text { hospitalizations }\end{array}$ & 17.29 & 20.04 & 137.000 & .445 \\
\hline CIS-APP & 18.43 & 19.35 & 153.000 & .811 \\
\hline UPSA-2-PT total & 14.14 & 21.96 & 93.000 & $.033^{*}$ \\
\hline
\end{tabular}

The accessibility and quality of mental health services tends to vary in more isolated and rural areas, posing an additional obstacles to patients and caretakers. In addition to fighting isolation and stigma, it is of utmost importance for stakeholders to acknowledge the pressing need for investment in the mental health system and the recovery of the human potential of the chronically ill, allocating more public and private resources to providing adequate intervention and psychosocial assistance for families and patients nationwide.

\section{References}

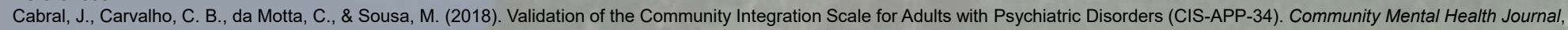
54(5), 673-681. https://doi.org/10.1007/s10597-017-0228-2

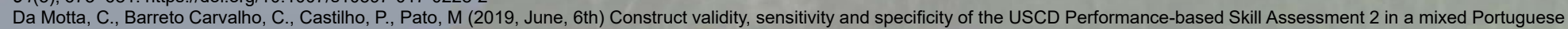
sample (version 2). SageSubmissions. DOI: 10.31124/advance.8067641

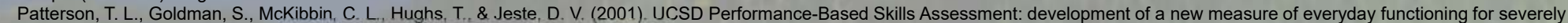
mentally ill adults. Schizophrenia Bulletin, 27(2), 235-245. https://doi.org/10,1093/oxfordjournals.schbul.a006870 